
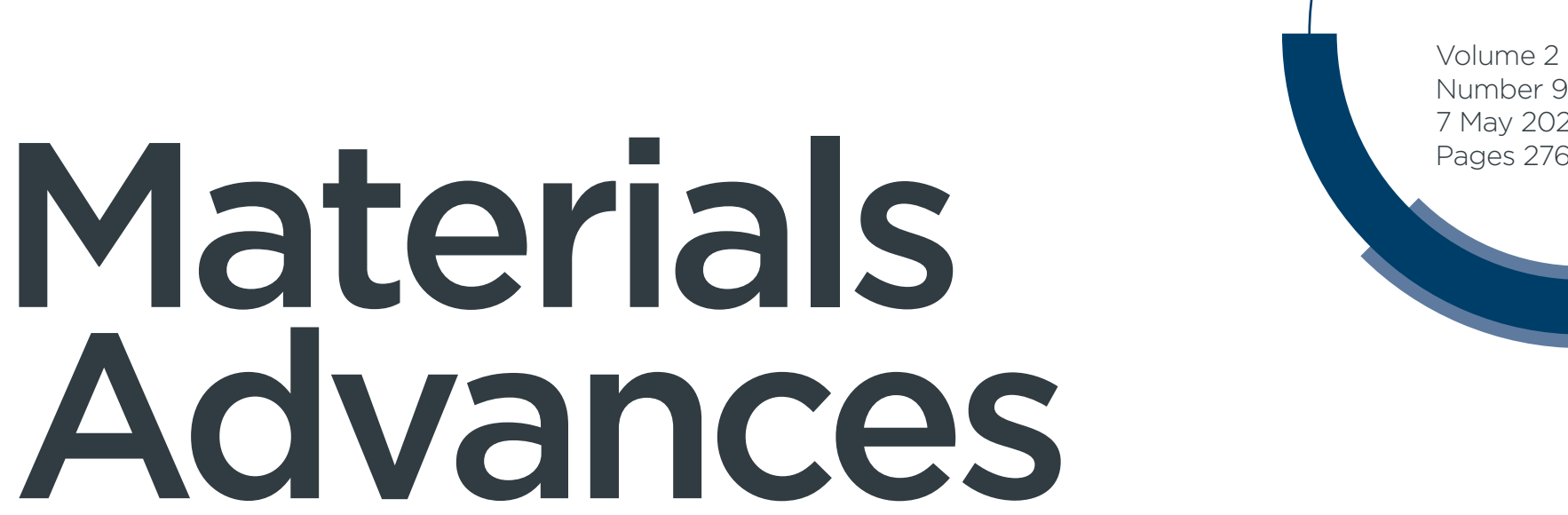

Number 9

7 May 2021

Pages 2763-3122

8

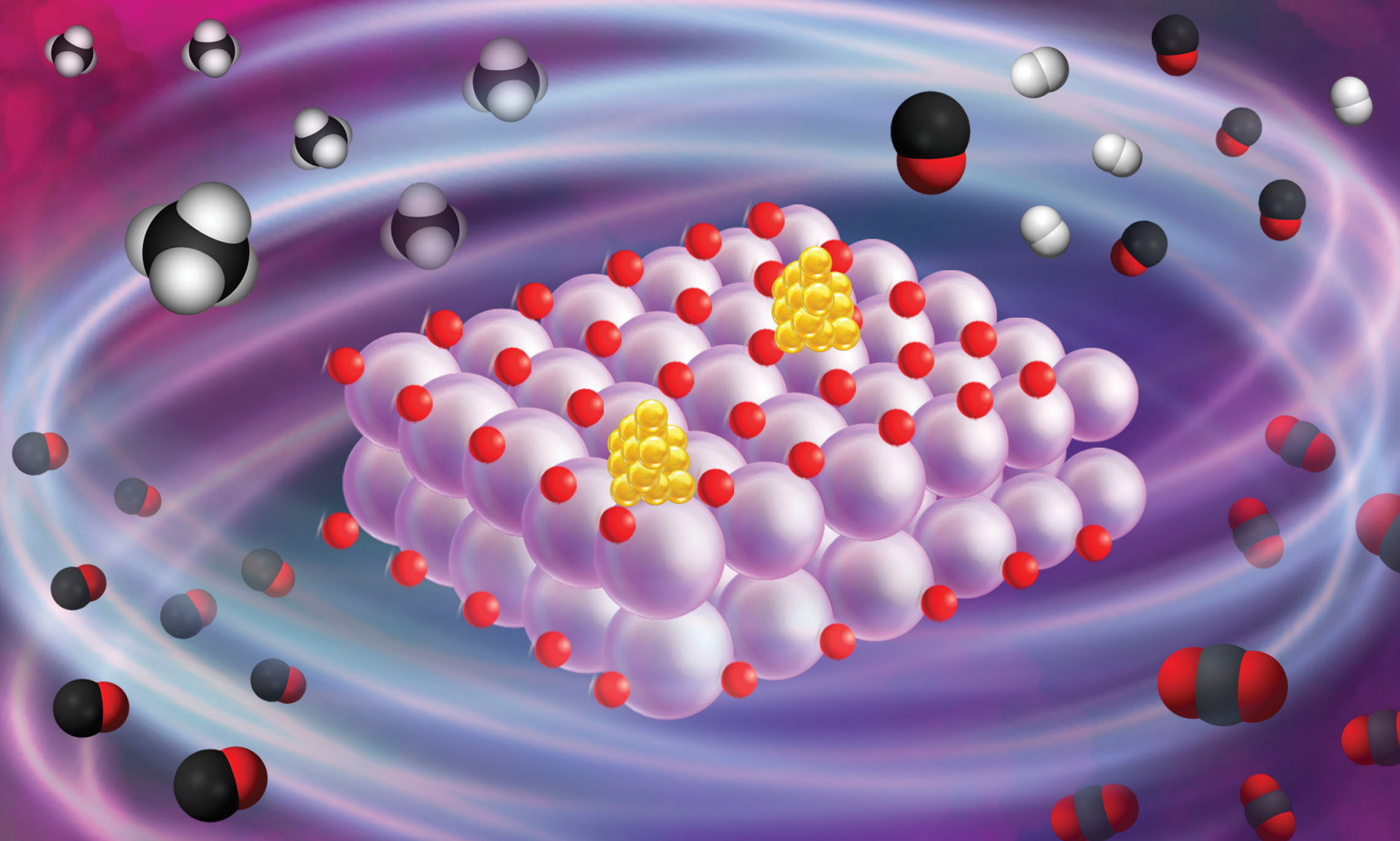


Check for updates

Cite this: Mater. Adv., 2021, 2, 2924

Received 18th January 2021, Accepted 23rd February 2021

DOI: $10.1039 / \mathrm{d} 1 \mathrm{ma} 00044 \mathrm{f}$

rsc.li/materials-advances

\title{
Boosting methane partial oxidation on ceria through exsolution of robust $\mathrm{Ru}$ nanoparticles $\dagger$
}

\author{
A. J. Carrillo, (D) L. Navarrete, M. Laqdiem, M. Balaguer and J. M. Serra (D)*
}

\begin{abstract}
Finding sustainable routes for the transformation of $\mathrm{CO}_{2}$ into fuels and added-value chemicals is key for mitigating greenhouse gas emission. In this respect, chemical-looping reforming coupled with $\mathrm{CO}_{2}$ splitting emerges as a promising technology to produce syngas, using waste or solar heat as an energy source. It relies on metal oxides that act as redox intermediates and, thus, the stability and catalytic activity of the oxides are crucial. For that purpose, ceria has been widely used due to its superior multicyclic stability and fast $\mathrm{CO}_{2}$ splitting kinetics. However, it also presents low capacity for oxygen exchange or supply compared with other oxides and slow methane partial oxidation kinetics, which is normally improved by cationic doping or catalytic surface activation via metal impregnation. The high temperatures $\left(900{ }^{\circ} \mathrm{C}\right.$ ) required for these reactions lead to catalyst deactivation over time due to sintering of metallic clusters. In order to circumvent this issue, in this work we have utilized the exsolution method to create uniformly dispersed Ru nanoparticles (ca. $5 \mathrm{~nm}$ ) that remain anchored to the cerium oxide backbone, guaranteeing its microstructural stability and catalytic activity over prolonged cycling. We provide evidence for metallic Ru exsolution and further demonstrate the outstanding benefits of exsolved nanoparticles in the partial oxidation of methane following a chemicalloop reforming scheme, especially in the temperature range in which industrial waste heat could be used as an energy source to drive the reaction. Remarkably, at $700{ }^{\circ} \mathrm{C}$ surface functionalization with exsolved Ru nanoparticles enables high $\mathrm{CO}$ selectivity (99\% versus $62 \%$ for $\mathrm{CeO}_{2}$ ) and about 2 orders of magnitude faster $\mathrm{H}_{2}$ production rates. The dispersion and size of the exsolved $\mathrm{Ru}$ nanoparticles were maintained after a durability test of 20 chemical loops at $900{ }^{\circ} \mathrm{C}$, indicating their robustness. Overall, the results presented here point towards the unique characteristics of nanoparticle exsolution for preventing agglomeration, which could find application in other catalytic or electrochemical processes for target hydrocarbon production.
\end{abstract}

\section{Introduction}

The intensification of chemical processes through the implementation of membrane reactors or chemical-looping schemes ${ }^{1}$ is an attractive alternative for the sustainable production of fuels with reduced $\mathrm{CO}_{2}$ footprint and increased exergy efficiency. ${ }^{2,3}$ In particular, chemical-looping reforming of methane (e.g. natural gas or biogas) coupled with $\mathrm{CO}_{2}$ splitting represents a unique niche for production of fuels utilizing two greenhouse gases as reagents. ${ }^{4}$ In the first step, $\mathrm{CH}_{4}$ is partially oxidized with the lattice oxygen of a metal oxide, $\mathrm{CeO}_{2}$ in this case (eqn (1); Fig. 1). This reaction results in the production of $\mathrm{H}_{2}$ and $\mathrm{CO}$, known as syngas, in a 2:1 molar ratio, which is ideal for further

Instituto de Tecnología Química, Universitat Politècnica de València-Consejo Superior de Investigaciones Cientificias, Avenida Los Naranjos $s / n$, 46022 Valencia, Spain. E-mail: jmserra@itq.upv.es $\dagger$ Electronic supplementary information (ESI) available. See DOI: 10.1039/ d1ma00044f processing into liquid fuels via the Fischer-Tropsch process. In the second step, the reduced metal oxide is reoxidized with $\mathrm{CO}_{2}$, producing $\mathrm{CO}$ (eqn (2)). Importantly, the first step, which is an endothermic reaction occurring at high temperatures (800-1000 ${ }^{\circ} \mathrm{C}$ ), could be driven with waste ${ }^{5}$ or concentrated solar heat ${ }^{6-8}$

$$
\begin{gathered}
\mathrm{CH}_{4}+1 / \delta \mathrm{CeO}_{2} \rightarrow\left(\mathrm{CO}+2 \mathrm{H}_{2}\right)+1 / \delta \mathrm{CeO}_{2-\delta} \\
\mathrm{CO}_{2}+1 / \delta \mathrm{CeO}_{2-\delta} \rightarrow 1 / \delta \mathrm{CeO}_{2}+\mathrm{CO} \\
\text { Net reaction: } \mathrm{CH}_{4}+\mathrm{CO}_{2} \rightarrow 2 \mathrm{CO}+2 \mathrm{H}_{2}
\end{gathered}
$$

This 2-step cyclic process presents several operational advantages. First, the main side reaction in thermocatalytic dry reforming, reverse water gas shift, is avoided. Secondly, carbon depositions caused by methane cracking in the first step could be transformed into CO during the second step by the Boudouard reaction. ${ }^{9}$ To guarantee the feasibility of the 
process, it is key to find stable redox materials that could withstand repeated high-temperature thermochemical cycling. In this respect, ceria has been widely studied due to its high structural stability at high temperatures and fast $\mathrm{CO}_{2}$ splitting kinetics, ${ }^{6,10}$ based on its performance tested in solar-driven reactors. ${ }^{9,11-13}$ However, the limited oxygen-exchange capacity of ceria could hamper its further applicability. In order to overcome this problem, doping with other cations, such as $\mathrm{Zr}^{14}$ or $\mathrm{La}^{5}{ }^{5}$ has been employed in order to increase the reducibility of cerium oxides and, subsequently, the fuel yields obtained by $\mathrm{H}_{2} \mathrm{O}$ and/or $\mathrm{CO}_{2}$ splitting. Morphological modifications ${ }^{15}$ or combinations in the form of composites with other metal oxides such as perovksites ${ }^{16}$ or binary oxides ${ }^{17,18}$ have been also successfully tested. Additionally, during the methane partial oxidation (MPO) step, most literature reports show syngas selectivity far from $100 \%,{ }^{6}$ which results from the combustion of $\mathrm{CH}_{4}$ with readily available oxygen anions at the $\mathrm{CeO}_{2}$ surface producing $\mathrm{CO}_{2}$ and $\mathrm{H}_{2} \mathrm{O}$. In order to solve this problem, surface promotion with metallic nanoparticles is commonly used in chemical looping reforming. ${ }^{2}$ In the case of $\mathrm{CeO}_{2}$, noble metals such as $\mathrm{Pt}$ or $\mathrm{Rh}^{19}$ or $\mathrm{Ni}$ in Ti-doped $\mathrm{CeO}_{2}{ }^{20}$ have been employed to suppress the formation of oxygenated molecules and increase $\mathrm{H}_{2}$ and $\mathrm{CO}$ selectivity. In the latter case, Ni decorated Ti-doped $\mathrm{CeO}_{2}$ resulted in $\mathrm{CO}$ selectivity $\left(S_{\mathrm{CO}}\right)$ values of $c a .80 \% .^{20}$ These metallic catalysts are commonly incorporated in the oxide surface via impregnation methods; however, at the high temperatures needed to drive the reduction of the metal oxide with methane, metal nanoparticles can suffer sintering with neighboring particles, which affects its catalytic activity during prolonged operation. ${ }^{21}$ In this sense, the exsolution method emerges as a promising alternative to obtain more durable metal nanoparticles with high catalytic activity. Nanoparticle exsolution consists of migration, under reductive atmospheres, of metal cations contained in the oxide lattice to the oxide surface, forming nanoparticles that remain anchored to the oxide backbone. ${ }^{22}$ The fact that the nanoparticles are socketed into the oxide surface imparts beneficial effects in terms of stability, avoiding nanoparticle sintering. ${ }^{23}$ For this reason, exsolution has gained considerable attention in the field of solid oxide fuel cells and electrolyzers, ${ }^{24,25}$ and more recently its application has been found to be promising in methane reforming reactions. ${ }^{26-29}$ For instance, Kousi and co-workers obtained exsolved and submerged Ni nanoparticles on $\mathrm{La}_{0.8} \mathrm{Ce}_{0.1} \mathrm{Ni}_{0.4} \mathrm{Ti}_{0.6} \mathrm{O}_{3}$ which synergistically enhanced the oxygen supply capacity. ${ }^{26}$ Additionally, Co incorporation into the B-site enables the activation of methane at temperatures as low as $450{ }^{\circ} \mathrm{C}^{30}$ For simultaneous methane partial oxidation coupled with $\mathrm{CO}_{2}$ splitting, Dimitrakopoulos et al. used a membrane reactor in which the exsolved nanoparticles were formed in situ during the reaction. ${ }^{31}$ More recently, Carrillo et al. demonstrated the beneficial effects of Co exsolution in the $\mathrm{La}_{0.6} \mathrm{Sr}_{0.4} \mathrm{Cr}_{0.8} \mathrm{Co}_{0.2} \mathrm{O}_{3}$ perovskite for syngas production, leading to faster MPO and $\mathrm{CO}_{2}$ splitting rates, higher syngas selectivity and stable nanoparticle size over 28 chemical loops. ${ }^{32}$ Regarding ceria and other fluorite type structures, the exsolution method has been scarcely explored. Recently, Naeem et al. demonstrated that $\mathrm{Ru}$ exsolution could boost the catalytic stability of $\mathrm{Sm}_{2} \mathrm{Ru}_{x}$ $\mathrm{Ce}_{2-x} \mathrm{O}_{7}$ materials for methane dry reforming, especially when compared with $\mathrm{Sm}$-Ce pyrochlores with impregnated $\mathrm{Ru}$ particles, denoting the beneficial effects of nanoparticle anchoring via exsolution. ${ }^{27}$ Based on these recent discoveries, in this work, we have applied the exsolution method to create robust $\mathrm{Ru}$ nanoparticles that could boost syngas production via chemical looping reforming of methane coupled with $\mathrm{CO}_{2}$ splitting, which to date has not been tested for ceria-based materials. The results reported herein denote the benefits of nanoparticle exsolution and could open the path for designing more stable cerium catalysts for other thermocatalytic applications or solid oxide electrochemical reactors and electrolyzers. ${ }^{33-36}$

\section{Results and discussion}

\subsection{Physicochemical insights into Ru nanoparticle exsolution} on $\mathrm{CeO}_{2}$

Ruthenium doped cerium oxide, $\mathrm{Ru}_{0.01} \mathrm{Ce}_{0.99} \mathrm{O}_{2}\left(\mathrm{Ru}-\mathrm{CeO}_{2}\right)$, was prepared via a modified version of the Pechini method (see the Experimental section). For benchmarking, $\mathrm{CeO}_{2}$ was also synthesized following the same method. According to the $\mathrm{X}$-ray diffractograms depicted in Fig. 1, pristine $\mathrm{Ru}-\mathrm{CeO}_{2}$ and $\mathrm{CeO}_{2}$ presented solely the reflections of fluorite $\mathrm{CeO}_{2}$, space group $\mathrm{Fm} 3 \mathrm{~m}$. Interestingly, incorporation of $\mathrm{Ru}$ into the fluorite crystal induced a lattice expansion according to the shift of the main reflection to lower $2 \theta$ values, pointing to the presence of a solid solution. The cubic lattice parameter, $a$, was calculated for both materials and was found to be 5.405 and $5.421 \AA$ for $\mathrm{CeO}_{2}$ and $\mathrm{Ru}-\mathrm{CeO}_{2}$, respectively. This result is somehow counterintuitive since the ionic radius for $\mathrm{Ce}^{4+}$ in 8 -fold coordination is

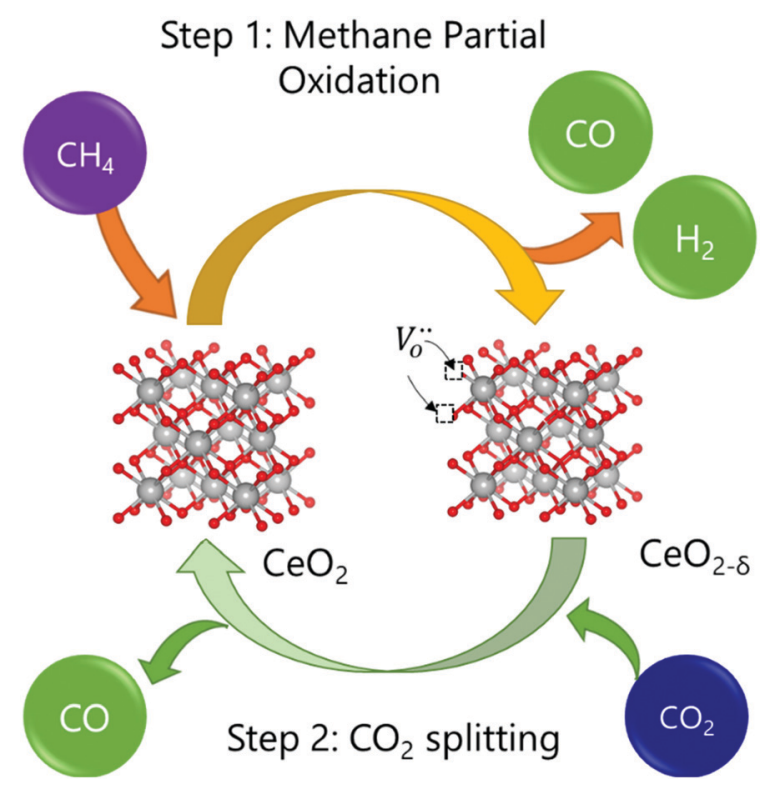

Fig. 1 Schematic of the chemical looping reforming of methane process studied in this work. In the first step, $\mathrm{CH}_{4}$ reacts with the lattice oxygen from $\mathrm{CeO}_{2}$, resulting in the formation of $\mathrm{CO}$ and $\mathrm{H}_{2}$. In the second step, $\mathrm{CO}_{2}$ reacts with the reduced oxide $\left(\mathrm{CeO}_{2-\delta}\right)$, replenishing the oxygen vacancies formed in the first step, and, subsequently, forming $\mathrm{CO}$. 

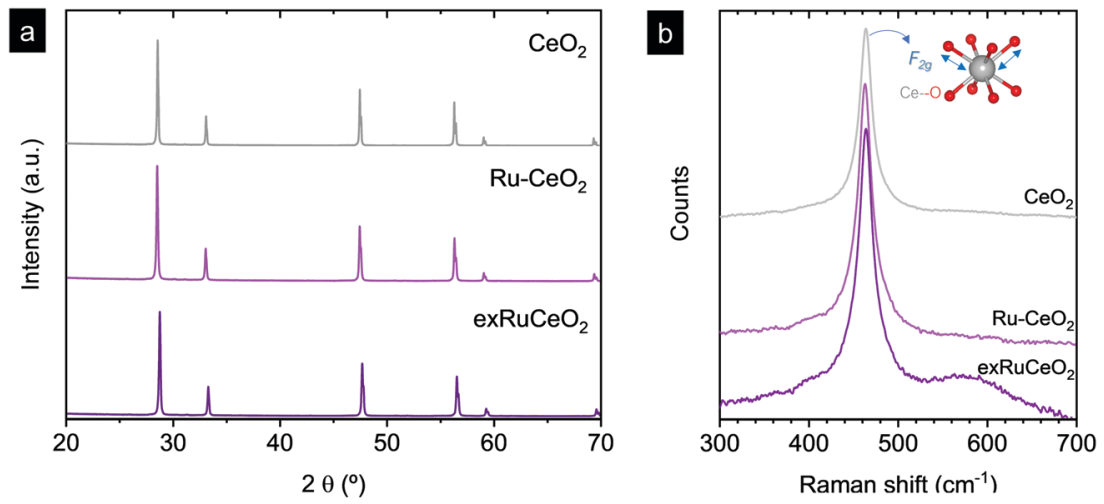

Fig. 2 X-ray diffraction patterns (a) and Raman spectra (b) for $\mathrm{Ru}-\mathrm{CeO}_{2}$ before and after exsolution performed at $900{ }^{\circ} \mathrm{C}$ for $2 \mathrm{~h}$ under $5 \%$ H flow $($ exRuCeO$)$ and for $\mathrm{CeO}_{2}$. Raman spectra were collected with a $785 \mathrm{~cm}^{-1}$ laser. The inner sketch in (b) depicts the vibration of oxygen anions around the Ce cation associated with the $F_{2 g}$ Raman mode.

$0.97 \AA$, whereas for $\mathrm{Ru}^{4+}$ (in 6-fold coordination) it is $0.64 \AA \AA^{37}$ which would suggest lattice shrinkage. However, this result is in accordance with previous works that reported a lattice expansion with Ru doping. ${ }^{38,39}$ In order to confirm the lattice expansion upon Ru substitution we analyzed the materials with Raman spectroscopy (Fig. 2b). Due to the high symmetry of the cubic fluorite structure, $\mathrm{CeO}_{2}$ has a unique Raman band ascribed to a one triply degenerate oxygen breathing mode of $F_{2 \mathrm{~g}}$ symmetry. ${ }^{40}$ This mode normally occurs at $465 \mathrm{~cm}^{-1}$; however, under the instrumental conditions used here, a red laser of $785 \mathrm{~cm}^{-1}$ wavelength, the $F_{2 \mathrm{~g}}$ peak for undoped $\mathrm{CeO}_{2}$ is at $463.7 \mathrm{~cm}^{-1}$. Upon $\mathrm{Ru}$ incorporation, the mode slightly shifted towards lower wavenumbers, $463.3 \mathrm{~cm}^{-1}$, which corroborates the lattice expansion observed by XRD. Interestingly, no bands associated with oxygen vacancies, the region between 550 and $600 \mathrm{~cm}^{-1},{ }^{27}$ were observed for $\mathrm{Ru}-\mathrm{CeO}_{2}$.

Fig. 2a also shows the XRD diffraction patterns for $\mathrm{Ru}-\mathrm{CeO}_{2}$ material after the exsolution process performed at $900{ }^{\circ} \mathrm{C}$ for $2 \mathrm{~h}$ under a $5 \% \mathrm{H}_{2}$ atmosphere, revealing that the fluorite crystal phase prevailed after the reductive treatment without the appearance of any secondary phase. However, when scrutinizing the materials' morphology before and after exsolution, important differences were observed. Fig. 3 depicts the SEM images of $\mathrm{Ru}-\mathrm{CeO}_{2}$ before and after the exsolution treatment. Fig. 3a reveals that $\mathrm{Ru}-\mathrm{CeO}_{2}$ is formed by aggregates of necked micron-sized particles. Fig. S1 (ESI $\dagger$ ) shows the EDX elemental analysis of the pristine material. However, after $2 \mathrm{~h}$ reduction in $5 \% \mathrm{H}_{2}$, well-dispersed nanoparticles emerged over the oxide surface indicative of nanoparticle exsolution (Fig. 3b). Turning back to the XRD diffraction, the exsolution treated $\mathrm{Ru}-\mathrm{CeO}_{2}$ sample $\left(\mathrm{exRuCeO}_{2}\right)$ experienced a shift towards higher $2 \theta$ values, denoting lattice shrinkage. That is to say, exRuCeO presented a cubic lattice parameter, $a$, of $5.413 \AA$, whereas for the pristine sample it was $5.421 \AA$. This slight lattice contraction was also observed in the Raman spectra depicted in Fig. $2 \mathrm{~b}$. The $F_{2 \mathrm{~g}}$ peak position for exRuCeO ${ }_{2}$ is at $464.5 \mathrm{~cm}^{-1}$, which is one wavenumber higher compared to that for $\mathrm{Ru}-\mathrm{CeO}_{2}$. In addition, exRuCeO$_{2}$ exhibited the Raman modes ascribed to oxygen vacancies at around $550-600 \mathrm{~cm}^{-1} .{ }^{41}$ This indicates that the
As-prepared

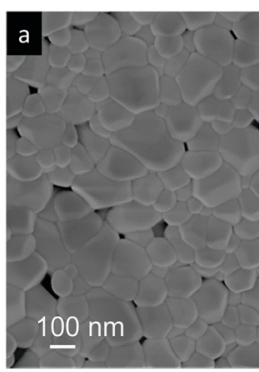

d

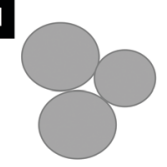

Fig. 3 SEM images of Ru-doped $\mathrm{CeO}_{2}$ samples: (a) pristine and after exsolution treatment for (b) $2 \mathrm{~h}$ and (c) $5 \mathrm{~h}$ at $900{ }^{\circ} \mathrm{C}$ under a $5 \% \mathrm{H}_{2}$ atmosphere. (d) Schematic depicting the morphology transformations at each stage.

exsolution treatment in the reductive atmosphere triggers the creation of oxygen vacancies in addition to the exsolved nanoparticles. Although both XRD and Raman analyses point toward lattice contraction upon nanoparticle exsolution, the origin of this phenomenon is not clear. Previous reports on reduction of $\mathrm{Ru}-\mathrm{CeO}_{2}$ at $500{ }^{\circ} \mathrm{C}$ in a $\mathrm{H}_{2}$ atmosphere showed a slight lattice expansion upon reduction; ${ }^{38}$ however, in that work the presence of exsolved Ru nanoparticles was not inferred. Under the present reductive atmosphere, the lattice oxygen reacts with $\mathrm{H}_{2}$ giving rise to electrons and oxygen vacancies, as demonstrated by Raman (Fig. 2b), which in the Kroger-Vink notation can be written as

$$
\mathrm{H}_{2}(\mathrm{~g})+\mathrm{O}_{\mathrm{O}}^{\mathrm{X}} \rightarrow \mathrm{V}_{\mathrm{O}}^{\bullet \bullet}+2 \mathrm{e}^{-}+\mathrm{H}_{2} \mathrm{O}(\mathrm{g})
$$

Subsequently, the oxidation state of cerium cations will be lowered according to $\mathrm{Ce}^{4+}+\mathrm{e}^{-} \rightarrow \mathrm{Ce}^{3+} \cdot{ }^{42}$ Commonly, it has 
been believed that lattice expansion of $\mathrm{CeO}_{2}$ upon reduction has been ascribed to the larger ionic radii of $\mathrm{Ce}^{3+}(1.143 \AA)$ compared to that of $\mathrm{Ce}^{4+}(0.97 \AA)$ cations. However, Muhich demonstrated that $\mathrm{Ce}^{3+}-\mathrm{O}^{2-}$ elongation can be compensated by $\mathrm{Ce}^{4+}-\mathrm{O}$ contraction, with the lattice expansion being driven by non-counterpoised forces. ${ }^{43}$ Anyhow, the nucleation of exsolved metallic nanoparticles compensates to a certain extent the expansion with contraction, ${ }^{42}$ which for this particular case, $\mathrm{Ru}^{4+}+4 \mathrm{e}^{-} \rightarrow \mathrm{Ru}^{0}$, could be higher explaining the slight lattice contraction upon metallic exsolution. In order to shed more light on this matter, we analyzed these three materials with Temperature Programmed Reduction (TPR). The TPR results (Fig. S2, ESI $\dagger$ ) showed a common peak at ca. $800{ }^{\circ} \mathrm{C}$ peak maximum, ascribed to the reduction of the $\mathrm{Ce}^{4+}$ bulk species. ${ }^{44}$ Interestingly, for both $\mathrm{CeO}_{2}$ and $\mathrm{RuCeO}_{2}$ this peak is located at $800{ }^{\circ} \mathrm{C}$. Normally, partial substitution of $\mathrm{Ce}^{4+}$ in doped ceria materials leads to a shift of this peak toward lower temperatures due to the creation of oxygen vacancies that facilitate oxygen diffusion. ${ }^{45,46}$ However, in this case Ru-doping did not result in the same effect, which might corroborate that $\mathrm{Ru}$ cations are located in interstitial positions, rather than partially substituting the $\mathrm{Ce}^{4+}$ cations, which results in the lattice expansion. After the exsolution treatment $\left(5 \% \mathrm{H}_{2}, 900{ }^{\circ} \mathrm{C}, 2 \mathrm{~h}\right)$ of the exRuCeO${ }_{2}$ material, the main peak shifted to $769{ }^{\circ} \mathrm{C}$. This shift to lower temperatures is ascribed to the presence of oxygen vacancies, as corroborated by Raman spectra. This fact is in principle beneficial for the MPO step, indicating that exRuCeO ${ }_{2}$ could outperform $\mathrm{CeO}_{2}$ at lower temperatures. Additionally, with the TPR analyses it was possible to determine the oxygen exchange/ supply capacity of the materials (see the Experimental section for more details). Our results indicate that the oxygen supply

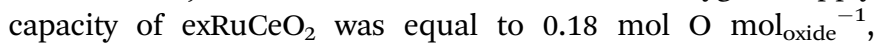
whereas for $\mathrm{CeO}_{2}$ it was $0.09 \mathrm{~mol} \mathrm{O} \mathrm{mol}_{\text {oxide }}{ }^{-1}$. Despite the increased value for exRuCeO${ }_{2}$ with respect to $\mathrm{CeO}_{2}$, the oxygen supply capacity is still below the values reported

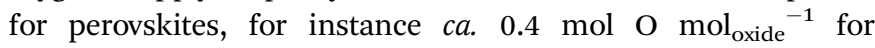
$\mathrm{La}_{0.8} \mathrm{Ce}_{0.1} \mathrm{Ni}_{0.4} \mathrm{Ti}_{0.6} \mathrm{O}_{3-\delta} \cdot{ }^{30}$

SEM analysis (Fig. 3b) of the sample reduced for $2 \mathrm{~h}$ in $\mathrm{H}_{2}$ at $900{ }^{\circ} \mathrm{C}$ reveals the formation of exsolved nanoparticles $(d \sim 2-5 \mathrm{~nm})$, well dispersed over all the facets of the oxide. Interestingly, when increasing the exsolution treatment up to $5 \mathrm{~h}$ (Fig. 3c) the nanoparticle size increases, as previously observed in $\mathrm{Ni}$ exsolution in perovskites, ${ }^{47,48}$ and grow mainly in the edges of the oxide particles, which progressively change from a rounded-like shape into a more faceted morphology caused by a longer exposure to the reductive environment. The changes in the exsolved nanoparticle habitus depending on time are reflected in the schematic depicted in Fig. $3 \mathrm{~d}$.

We now turn to TEM to further analyze the size and level of anchorage of the exsolved $\mathrm{Ru}$ nanoparticles. Fig. 4a depicts some grains of exRuCeO $\mathrm{C}_{2}$ and the presence of exsolved nanoparticles over the oxide backbone. At higher magnifications (Fig. 4b), it is possible to observe that the nanoparticle is embedded in the oxide backbone, confirming the level of anchorage characteristic from metal nanoparticle exsolution. ${ }^{49}$ Fig. 4c shows the HAADF-STEM image of exRuCeO ${ }_{2}$, in which it

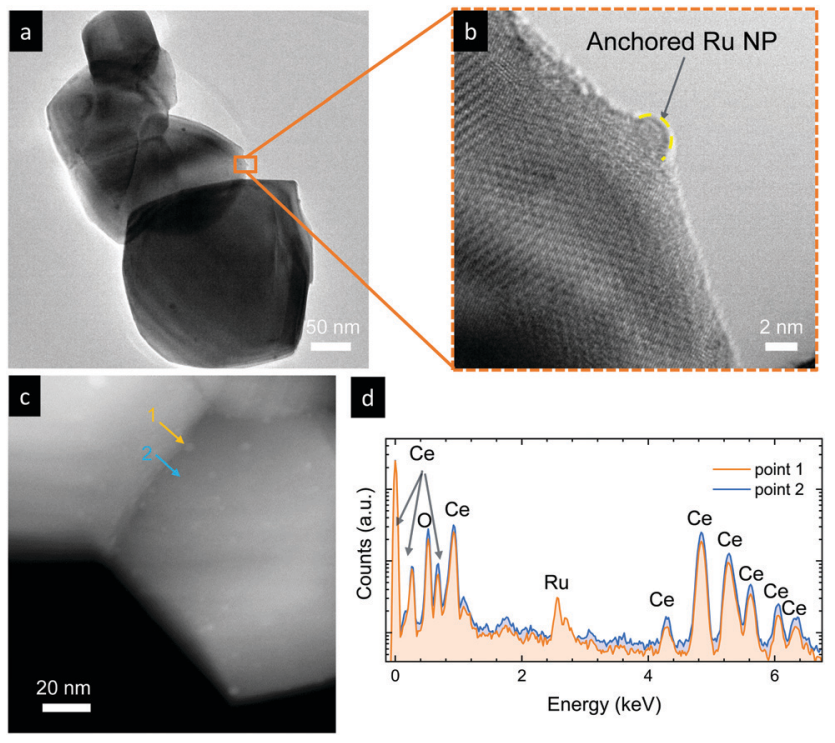

Fig. 4 ( $a$ and b) TEM images of Ru-doped $\mathrm{CeO}_{2}$ after exsolution treatment for (b) $2 \mathrm{~h}$ at $900{ }^{\circ} \mathrm{C}$ in a $5 \% \mathrm{H}_{2}$ atmosphere. (c) HAADF-STEM image for the same material and (d) EDX point analysis of an exsolved nanoparticle (point 1) and the bare oxide surface (point 2).

is possible to observe the high and uniform dispersion of exsolved nanoparticles over the oxide backbone. EDX was utilized to further explore the nature of the exsolved nanoparticles (Fig. 4d), by analyzing two different zones in Fig. 4c, one pointing to an exsolved particle (point 1) and the other pointing to the oxide surface (point 2). By comparison, one can observe the higher concentration of $\mathrm{Ru}$ on the exsolved nanoparticles. Although $\mathrm{Ru}$ exsolution on $\mathrm{Sm}_{2} \mathrm{Ce}_{2} \mathrm{O}_{7}$ pyrochlores has been recently reported, ${ }^{27}$ to the best of our knowledge this work represents the first demonstration of $\mathrm{Ru}$ exsolution from the $\mathrm{CeO}_{2}$ fluorite host.

To further explore the nature of the exsolved nanoparticles we performed X-ray photoemission spectroscopy (XPS; Fig. 5). In order to analyze the oxidation state of $\mathrm{Ru}$, we checked the Ru3p core shell, since Ru5d overlaps with C1s. ${ }^{34,38,39}$ Fig. 5a compares the Ru3p spectra for $\mathrm{Ru}-\mathrm{CeO}_{2}$ before and after exsolution (i.e., for exRuCeO ${ }_{2}$ ). The $\mathrm{Ru}_{3} \mathrm{p}_{3 / 2}{ }^{50}$ binding energy for $\mathrm{Ru}-\mathrm{CeO}_{2}$ was observed at $463.26 \mathrm{eV}$, whereas after exsolution, it shifted to $461.64 \mathrm{eV}$, indicative of the $\mathrm{Ru}$ metal. ${ }^{34,38,39}$ This shift indicates that for the $\mathrm{Ru}-\mathrm{CeO}_{2}$ sample $\mathrm{Ru}$ is in the 4+ oxidation state, and after the $2 \mathrm{~h}$ reduction in $5 \% \mathrm{H}_{2}$ at $900{ }^{\circ} \mathrm{C}$, all the $\mathrm{Ru}$ at the surface is in the metal state, corroborating that the exsolved nanoparticles observed by SEM (Fig. 3) and TEM (Fig. 4) are solely composed of the Ru metal. XPS analysis of Ce3d core-level spectra are depicted in Fig. $5 b$. The $3 d_{5 / 2}$ and $3 d_{3 / 2}$ components correspond to $\mathrm{v}$ and $\mathrm{u}$, respectively, whereas $\mathrm{v}^{\prime \prime}, \mathrm{v}^{\prime \prime \prime}$ and $\mathrm{u}^{\prime \prime}, \mathrm{u}^{\prime \prime \prime}$ are the satellites, respectively. Additionally, the doublets $\mathrm{v}_{0}, \mathrm{u}_{0}$ and $\mathrm{v}^{\prime}, \mathrm{u}^{\prime}$ correspond to $\mathrm{Ce}^{3+} \cdot{ }^{51-53}$ A detailed description of the deconvolution of each of these components can be found in the ESI $\dagger$ (Tables S1-S3,). According to the spectra depicted in Fig. $5 \mathrm{~b}$, it can be inferred that there is little presence of $\mathrm{Ce}^{3+}$ in the surface of $\mathrm{Ru}-\mathrm{CeO}_{2}$, which slightly increases after exsolution, as revealed for exRuCeO $\mathrm{C}_{2}$. The $\mathrm{O} 1 \mathrm{~s}$ spectra depicted in Fig. $5 \mathrm{c}$ indicate that for the three materials the major component is 

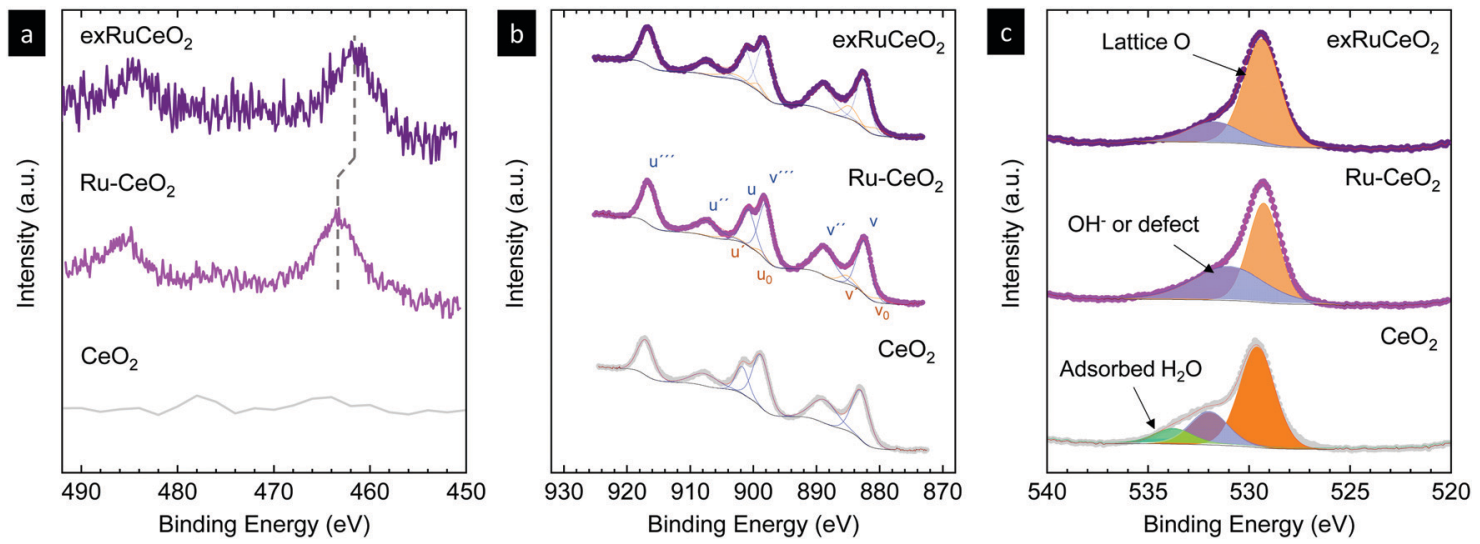

Fig. 5 X-ray photoemission spectra of (a) Ru3p, (b) $\mathrm{Ce} 3 \mathrm{~d}$ and (c) $\mathrm{O} 1$ s core levels of $\mathrm{CeO}_{2}$ and Ru-doped $\mathrm{CeO}_{2}$ before $\left(\mathrm{Ru}-\mathrm{CeO}_{2}\right)$ and after exsolution of Ru nanoparticles (exRuCeO ${ }_{2}$ ).

located at binding energies around $529 \mathrm{eV}$, which is generally ascribed to the lattice oxygen in oxides. ${ }^{51}$ In addition, for $\mathrm{Ru}-\mathrm{CeO}_{2}$ and $\mathrm{exRuCeO}_{2}$ there is a feature around $531 \mathrm{eV}$ representative of oxygen anions in the vicinity of oxygen vacancies, indicating the presence of oxygen vacancy sites in the surface of these materials. For the case of $\mathrm{CeO}_{2}$, the components around 533 and $534 \mathrm{eV}$ could be ascribed to adsorbed species.

In this section, we have presented the thorough physicochemical characterization of the materials before and after exsolution, confirming the presence of anchored metallic $\mathrm{Ru}$ nanoparticles over cerium-based oxides. In the following, the performance of exRuCeO ${ }_{2}$ for chemical looping methane reforming coupled with $\mathrm{CO}_{2}$ splitting will be interrogated, paying special attention to the reaction rate improvement and nanoparticle stability after prolonged cycling.

\subsection{Improving methane partial oxidation with Ru exsolution}

Chemical looping methane reforming coupled with $\mathrm{CO}_{2}$ splitting reactions was performed in a fixed-bed tubular quartz reactor and the gas production was monitored via mass spectrometry. First, we focus on determining the impact of Ru nanoparticles on syngas production, and for that, we benchmark exRuCeO against $\mathrm{CeO}_{2}$. As commented in the introduction, one of the main drawbacks of $\mathrm{CeO}_{2}$ for chemical looping reforming is that it presents slow syngas production during the partial oxidation of methane, which is the first step of this redox cyclic process (Fig. 1). In this first set of experiments, chemical looping reforming coupled with $\mathrm{CO}_{2}$ splitting was assessed at three different temperatures $\left(900,800,700{ }^{\circ} \mathrm{C}\right)$ for both materials, i.e., exRuCeO $\mathrm{O}_{2}$ and $\mathrm{CeO}_{2}$. Here, it should be noted that the exsolution process was carried out inside the reactor, prior to the chemical looping reforming tests. We first assessed the influence of temperature on the chemical looping reforming performance of $\mathrm{CeO}_{2}$. Fig. 6a depicts the reactions occurring at $900{ }^{\circ} \mathrm{C}$, which start with the injection of a stream of $5 \mathrm{vol} \%$ of $\mathrm{CH}_{4}$, resulting in the formation of $\mathrm{H}_{2}$ and $\mathrm{CO}$, which are the products of the partial oxidation of methane, and $\mathrm{CO}_{2}$, which results from the complete oxidation of $\mathrm{CH}_{4}$ with the lattice oxygen. For further information, Fig. S3 (ESI $\dagger$ ) also shows the
$\mathrm{CH}_{4}$ curve in order to show the methane consumption, as well as the $\mathrm{O}_{2}$ production curve, which clearly illustrates the absence of this gas during the experiments. The formation of $\mathrm{CO}_{2}$ occurred at the beginning of the reaction, which is indicative of $\mathrm{CH}_{4}$ reaction with readily available oxygen species at the surface of the ceria. ${ }^{54}$ The $\mathrm{CO}_{2}$ production in the first stage of the reaction lasted for $c a .1 \mathrm{~min}$. Simultaneously, the formation of $\mathrm{H}_{2}$ and $\mathrm{CO}$ occurred steadily until $\mathrm{CH}_{4}$ injection was suppressed. At $900{ }^{\circ} \mathrm{C}$, CO selectivity, $S_{\mathrm{CO}}$, was equal to $80 \%$ because of the prominent formation of $\mathrm{CO}_{2}$; see Fig. 7 for the selectivity data at the different temperatures tested. The peak gas production rate was 2.9 and $1.3 \mathrm{~mL} \mathrm{~min}^{-1} \mathrm{~g}^{-1}$ for $\mathrm{H}_{2}$ and $\mathrm{CO}$, respectively, resulting in a $\mathrm{H}_{2}$ : $\mathrm{CO}$ ratio slightly higher than the stoichiometric 2:1 proportion, indicative of $\mathrm{CH}_{4}$ decomposition into solid $\mathrm{C}$ and additional $\mathrm{H}_{2}$ formation. Once $\mathrm{CH}_{4}$ injection was complete, Ar was flushed to purge the reactor for $2 \mathrm{~min}$, followed by the injection of $\mathrm{CO}_{2}(5 \mathrm{vol} \%)$. As mentioned in the introduction (Fig. 1), the methane partial oxidation step generates oxygen vacancies in the cerium oxide, since the lattice oxygen reacts with $\mathrm{CH}_{4}$. Thus, in the oxidation step, $\mathrm{CO}_{2}$ reacts with the reduced cerium oxide $\left(\mathrm{CeO}_{2-\delta}\right)$, replenishing most of the oxygen vacancies with oxide anions, and subsequently forming $\mathrm{CO}$, as observed in the second step in Fig. 6a. Once $\mathrm{CO}_{2}$ is injected inside the reactor, a fast $\mathrm{CO}$ production is observed (peak production rate of $18.2 \mathrm{~mL} \mathrm{~min}^{-1} \mathrm{~g}^{-1}$ ), that lasted for $2 \mathrm{~min}$ until $\mathrm{CO}_{2}$ splitting reaction reached equilibrium. This fact indicates that this $\mathrm{CeO}_{2-\delta}$-reoxidation step could be performed with shorter $\mathrm{CO}_{2}$ injections, which will eventually increase the $\mathrm{CO}_{2}$ conversion per cycle, denoting the high extent of operational tunability and room for optimization of this technology.

The influence of temperature on the chemical looping reforming activity of $\mathrm{CeO}_{2}$ is depicted in Fig. $6 \mathrm{~b}$ (reaction at $800{ }^{\circ} \mathrm{C}$ ) and Fig. $6 \mathrm{c}$ (reaction at $700{ }^{\circ} \mathrm{C}$ ). Here, we would like to note that lowering the process temperature is beneficial to leverage industrial waste heat to drive the endothermic methane partial oxidation reaction. ${ }^{5}$ However, by lowering the reaction temperature, the driving force for the formation of oxygen vacancies in $\mathrm{CeO}_{2}$ and the activation of $\mathrm{CH}_{4}$ are also decreased since, thermodynamically, oxygen vacancy formation 
a

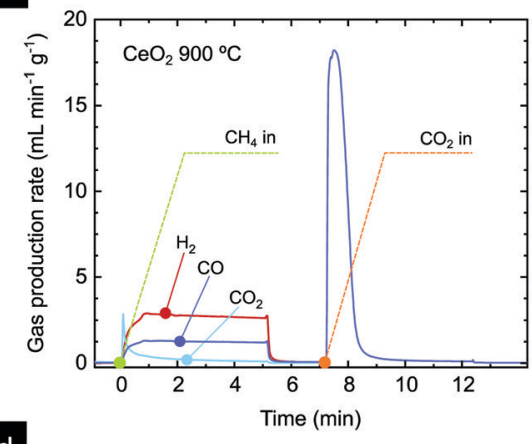

d

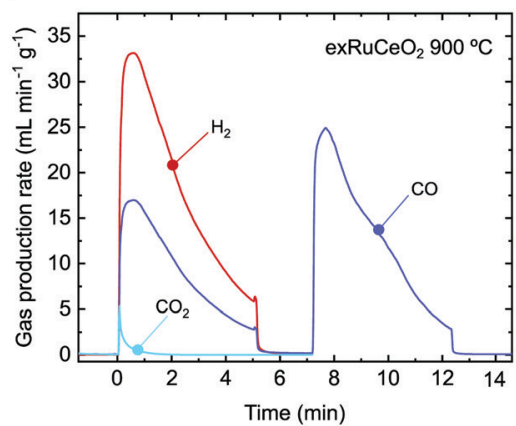

b

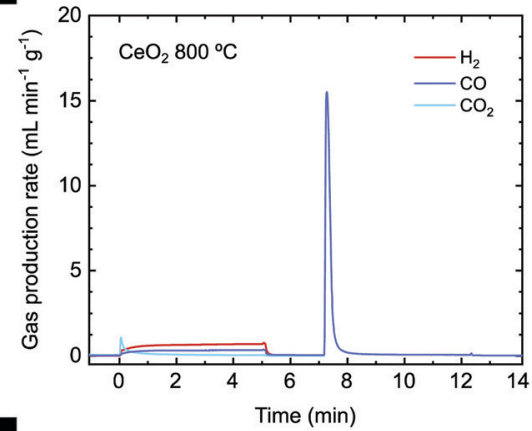

e

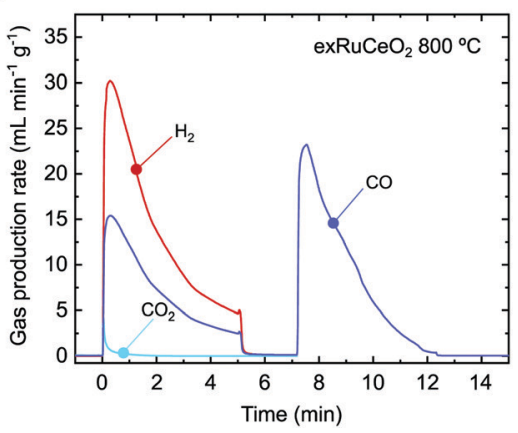

c

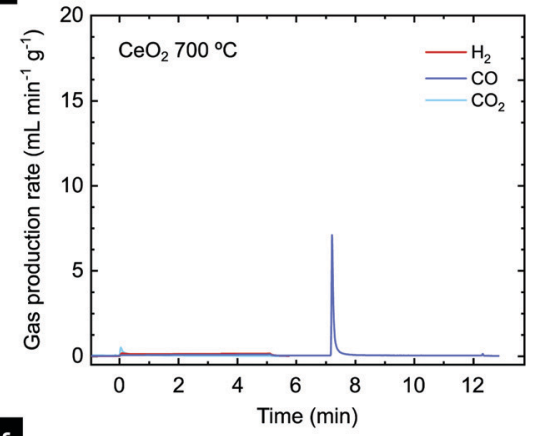

f

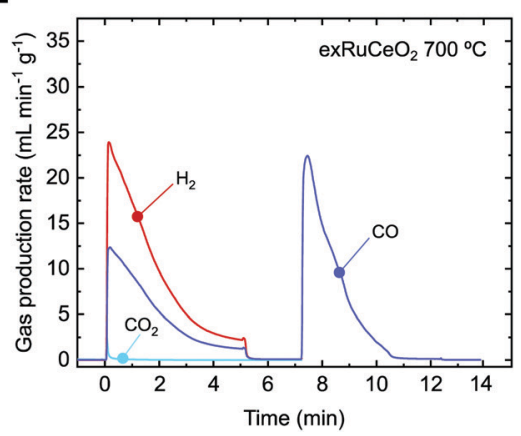

Fig. 6 Chemical looping gas production curves for $\mathrm{CeO}_{2}$ at (a) $900{ }^{\circ} \mathrm{C}$, (b) $800{ }^{\circ} \mathrm{C}$ and (c) $700{ }^{\circ} \mathrm{C}$, and exRuCeO 2 at (d) $900{ }^{\circ} \mathrm{C}$, (e) $800{ }^{\circ} \mathrm{C}$ and (f) $700{ }^{\circ} \mathrm{C}$. Each chemical loop consisted of 5 min methane partial oxidation (injection of $5 \% \mathrm{CH}_{4}$, total flow $100 \mathrm{~mL} \mathrm{~min}^{-1}$ ) and 5 min $\mathrm{CO}_{2}$ splitting (injection of $5 \%$ $\mathrm{CO}_{2}$, total flow $100 \mathrm{~mL} \mathrm{~min}{ }^{-1}$ ). The exsolution of exRuCeO 2 was performed inside a quartz reactor. For that purpose, $\mathrm{Ru}-\mathrm{CeO}_{2}$ was reduced under $5 \% \mathrm{H}_{2}$ for $2 \mathrm{~h}$ at $900{ }^{\circ} \mathrm{C}$.

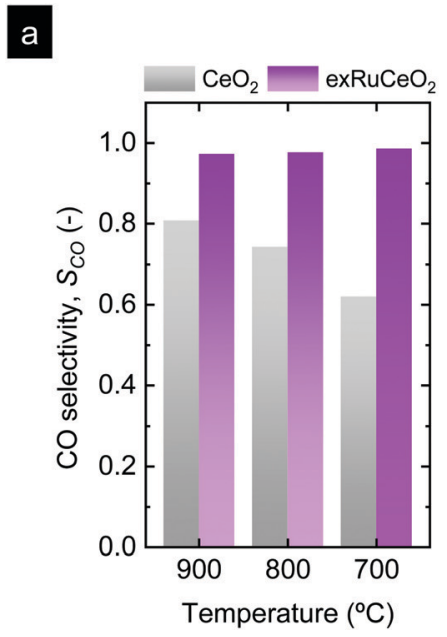

b

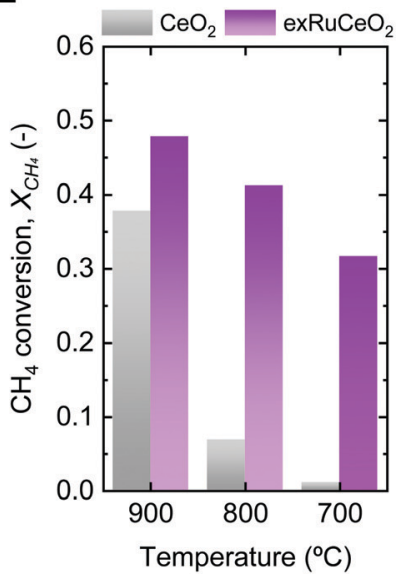

c

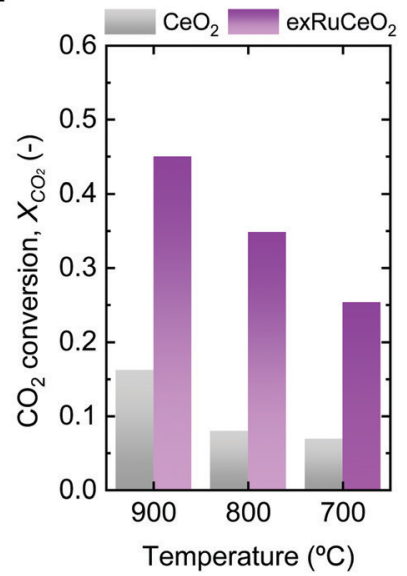

Fig. 7 Comparison of (a) selectivity, (b) $\mathrm{CH}_{4}$ conversion during the MPO step, and (c) $\mathrm{CO}_{2}$ conversion during the $\mathrm{CO}_{2}$ splitting step for the two materials tested.

in ceria is favored at higher temperatures. ${ }^{54}$ This fact implies that lower reduction extents, $\delta$, are achieved during the methane partial oxidation, which directly affects the CO production extent (yield and formation rate) in the subsequent $\mathrm{CO}_{2}$ splitting step (eqn (1) and (2)). This effect is illustrated in Fig. $6 \mathrm{~b}$ and c, i.e. lowering the reaction temperature drastically diminished the amount of $\mathrm{H}_{2}$ and $\mathrm{CO}$ produced in the first step, and hence the $\mathrm{CH}_{4}$ conversion, with peak $\mathrm{H}_{2}$ production rates of 0.76 and $0.18 \mathrm{~mL} \mathrm{~min}{ }^{-1} \mathrm{~g}^{-1}$, denoting one order of magnitude decrease in the syngas production of $\mathrm{CeO}_{2}$ by lowering $200{ }^{\circ} \mathrm{C}$. This temperature decrease also affected $S_{\mathrm{CO}}$, which decreased to $74 \%$ and $62 \%$ at 800 and $700{ }^{\circ} \mathrm{C}$, respectively. Fig. S4 (ESI $\dagger$ ) (a zoom-out of Fig. 6c) reveals that the $\mathrm{CO}_{2}$ production curve is even higher than the $\mathrm{H}_{2}$ and $\mathrm{CO}$ ones. In addition, the $\mathrm{CO}_{2}$ splitting rate and $\mathrm{CO}$ yield notably decreased at lower temperatures, as an effect of the lower amount of 
vacancies created in the methane activation step, which directly correlates with the amount of $\mathrm{CO}$ produced in the second step. The CO yields obtained were 14.1, 3.5 and $0.5 \mathrm{~mL} \mathrm{~g}^{-1}$ for 900,800 and $700{ }^{\circ} \mathrm{C}$, respectively. In addition, for the reaction at $900{ }^{\circ} \mathrm{C}$, there is a fraction of $\mathrm{CO}$ that was generated through the Boudouard reaction, in which deposited coke is gasified with $\mathrm{CO}_{2}$, increasing $\mathrm{CO}$ yield. In summary, these results provide evidence about the main challenges of $\mathrm{CeO}_{2}$ in chemical looping reforming, i.e. (i) low activity for methane partial oxidation; and (ii) syngas selectivity far from $100 \%$, both being drastically decreased with lowering the process temperature.

Fig. $6 \mathrm{~d}-\mathrm{f}$ show the results of catalytic tests using exRuCeO $\mathrm{O}_{2}$ as a redox material at 900,800 and $700{ }^{\circ} \mathrm{C}$, respectively. By comparing Fig. $6 \mathrm{a}$ and $\mathrm{d}$, the benefits of surface functionalization by exsolved $\mathrm{Ru}$ nanoparticles become noticeable. At $900{ }^{\circ} \mathrm{C}$ the $\mathrm{H}_{2}$ production

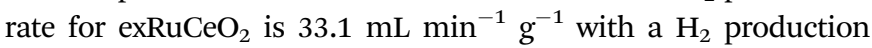
of $92 \mathrm{~mL} \mathrm{~g}^{-1}$. In contrast, the values achieved for $\mathrm{CeO}_{2}$ are $2.9 \mathrm{~mL} \mathrm{~min}^{-1} \mathrm{~g}^{-1}$ and $13.70 \mathrm{~mL} \mathrm{~g}^{-1}$, which are $\mathrm{ca}$. one order of magnitude lower. In addition, the gas production curve when using exRuCeO ${ }_{2}$ starts with a pronounced peak that progressively decays, which totally differs from the flattened profile exhibited for syngas production with $\mathrm{CeO}_{2}$. The amount of $\mathrm{CO}$ produced is $46.6 \mathrm{~mL} \mathrm{~g}^{-1}$, resulting in $\mathrm{a}_{2}$ : $\mathrm{CO}$ ratio of 1.98 close to the stoichiometric $2: 1$. In comparison $\mathrm{CeO}_{2}$ showed a $\mathrm{H}_{2}$ : $\mathrm{CO}$ ratio of 2.17 at $900{ }^{\circ} \mathrm{C}$, due to $\mathrm{CH}_{4}$ cracking into $\mathrm{H}_{2}(\mathrm{~g})$ and $\mathrm{C}(\mathrm{s})$. This is indicative of a higher resistance to carbon depositions ascribed to the presence of exsolved nanoparticles, as previously reported in the literature. ${ }^{23}$ Fig. $6 \mathrm{a}$ also shows that there is concomitant production of $\mathrm{CO}_{2}$, however, in a minor extent when compared with CO, resulting in a high $S_{\mathrm{CO}}$ of $97 \%$. These results highlight the benefits that exsolved $\mathrm{Ru}$ nanoparticles impart on improving the methane partial oxidation performance. However, it should be also kept in mind that exRuCeO $\mathrm{C}_{2}$ allocates oxygen vacancies prior to the reaction since during the exsolution treatment $\mathrm{H}_{2}$ was utilized to reduce the material and drive the exsolution of $\mathrm{Ru}$ nanoparticles. Warren and Scheffe pointed towards surface oxygen vacancies as active sites for methane activation, ${ }^{55}$ and recently demonstrated how the increase of oxygen vacancies in $\mathrm{CeO}_{2}$, in their case by not reaching full conversion in the previous $\mathrm{CO}_{2}$ splitting oxidation step, could greatly enhance the rate of syngas production. ${ }^{9}$

The higher syngas yield in the first step is an indicative of a higher extent of reduction for exRuCeO $\mathrm{O}_{2}$ when compared with $\mathrm{CeO}_{2}$, triggered by the presence of $\mathrm{Ru}$. As a result, in the subsequent $\mathrm{CO}_{2}$ splitting step, the $\mathrm{CO}$ yield (Fig. 6d) was also higher than for $\mathrm{CeO}_{2}$ (Fig. 6a) with 14.1 and $66 \mathrm{~mL} \mathrm{~g}^{-1}$, respectively. It can be also observed that for $\operatorname{exRuCeO}_{2}$, the $\mathrm{CO}_{2}$ splitting reaction did not achieve equilibrium in the $5 \mathrm{~min}$ $\mathrm{CO}_{2}$ injection, opposite to the behavior of $\mathrm{CeO}_{2}$, which reached full oxidation after 2 min exposure.

Similar to what happened to $\mathrm{CeO}_{2}$, lowering the temperature also affected the kinetics and syngas yield, although to a minor extent (Fig. 6e and f). In particular, the performance observed at $700{ }^{\circ} \mathrm{C}$ is remarkable (Fig. 6f), which is the temperature closer to the range needed for utilization of industrial waste heat as an energy source. For instance, the peak $\mathrm{H}_{2}$ production rate reaches $23.9 \mathrm{~mL} \min ^{-1} \mathrm{~g}^{-1}$ for exRuCeO ${ }_{2}$, whereas for $\mathrm{CeO}_{2}$ it is $0.18 \mathrm{~mL} \mathrm{~min}^{-1} \mathrm{~g}^{-1}$. This 2-order of magnitude increase in the syngas production rate at $700{ }^{\circ} \mathrm{C}$ illustrates the high catalytic activity of the $\mathrm{Ru}$ nanoparticles for the MPO into syngas. In addition, exRuCeO ${ }_{2}$ displayed $S_{\mathrm{CO}} \sim 99 \%$ at $700{ }^{\circ} \mathrm{C}$. Fig. 7b shows that methane conversions $\left(X_{\mathrm{CH} 4}\right) \sim 32 \%$ can be reached for exRuCeO${ }_{2}$ at $700{ }^{\circ} \mathrm{C}$ whereas for $\mathrm{CeO}_{2}$ just $1 \%$ conversions are observed. Nevertheless, it should be noted here that our experiments were not targeted for reaching higher conversions of $\mathrm{CH}_{4}$ or $\mathrm{CO}_{2}$, which could be improved by shortening the injection time or increasing the solid loading. For the $\mathrm{CO}_{2}$ splitting step, just a slight decrease is observed in the peak production rate when lowering the temperature. That is to say, CO production rates were 24.9, 23.2 and $22.4 \mathrm{~mL} \mathrm{~min}^{-1} \mathrm{~g}^{-1}$ at 900,800 and $700{ }^{\circ} \mathrm{C}$, respectively. However, since by lowering the temperature the amount of oxygen vacancies generated in the previous reduction step was also decreased, it was observed that $\mathrm{CO}_{2}$ splitting reaction reached equilibrium before the $5 \mathrm{~min} \mathrm{CO}_{2}$ injection was complete. That is to say, at $700{ }^{\circ} \mathrm{C}, \mathrm{CO}_{2}$ splitting reached equilibrium after $3 \mathrm{~min}$ of exposure to $\mathrm{CO}_{2}$ (Fig. 6f) ascribed to a lower amount of oxygen vacancies that should be replenished. This also affected the $\mathrm{CO}_{2}$ conversion values $\left(X_{\mathrm{CO} 2}\right)$ which increased with increasing temperature (Fig. 7c). The highest conversion was for exRuCeO ${ }_{2}$ at $900{ }^{\circ} \mathrm{C}$ with $\mathrm{ca}$. $45 \%$, whereas for $\mathrm{CeO}_{2}$ it was $c a .16 \%$ at the same temperature.

\subsection{Chemical activity and stability test of exsolved Ru nanoparticles}

In the previous section, the benefits of functionalizing the $\mathrm{CeO}_{2}$ oxide surface with $\mathrm{Ru}$ nanoparticles became visible, with a remarkable reaction activity improvement when compared with bare $\mathrm{CeO}_{2}$. Now, we assess the stability of the reaction over prolonged cycling at a fixed temperature as well as the stability of the Ru nanoparticles in harsher conditions. For that purpose, we conducted a 20-cycle chemical looping reforming test at $900{ }^{\circ} \mathrm{C}$. The reaction conditions were modified with respect to the previous section, viz., a 10 -fold higher concentration of $\mathrm{CO}_{2}$ (50 vol\%) was used for the 2nd step. The motivation for the increase of the $\mathrm{CO}_{2}$ partial pressure was 2-fold. The first was in order to assess the reaction in more realistic conditions in which more concentrated $\mathrm{CO}_{2}$ stream would be used. Second, we observed in Fig. $6 \mathrm{~d}$ that with 5 vol\% the $\mathrm{CO}_{2}$ splitting reaction did not reach equilibrium in the given $5 \mathrm{~min} \mathrm{CO}_{2}$ injection period. By increasing the $\mathrm{CO}_{2}$ partial pressure faster kinetics are expected, ${ }^{56}$ achieving full oxidation in the given time. By this way, the material will be fully oxidized in the subsequent reduction step under $\mathrm{CH}_{4}$, and, thus, the kinetic effect provided by the oxygen vacancies acting as active sites at the surface will be suppressed. Raman (Fig. 2b) and XPS analyses (Fig. 5c) proved that exRuCeO ${ }_{2}$ allocates oxygen vacancies before the first MPO reaction, which Warren and Scheffe showed to be vacancymediated. ${ }^{55}$ The syngas production curves during the 20-cycle chemical looping reforming test are shown in Fig. 8a, in which the syngas $\left(\mathrm{H}_{2}\right.$ and $\left.\mathrm{CO}\right)$ produced during the MPO and the $\mathrm{CO}$ produced during the $\mathrm{CO}_{2}$ splitting step are depicted. It can be observed that over the 20 cycles, the chemical activity of the 
a
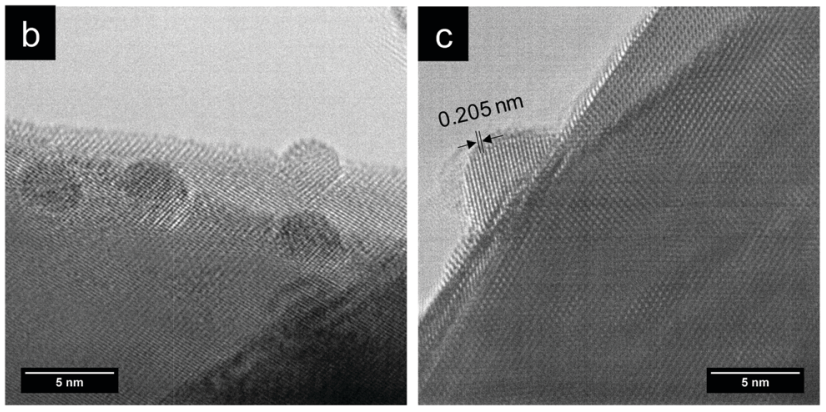

Fig. 8 (a) $\mathrm{H}_{2}$ and $\mathrm{CO}$ gas production curves obtained from a durability test carried out for exRuCeO${ }_{2}$, previously exsolved in a tubular furnace at $900{ }^{\circ} \mathrm{C}$ for $2 \mathrm{~h}$ under $5 \% \mathrm{H}_{2}$. The test consisted of 20 chemical loops, with each of them with first 5 vol\% $\mathrm{CH}_{4}$ injection for $5 \mathrm{~min}$, followed by a $2 \mathrm{~min}$ purge under pure $\mathrm{Ar}$, and 50 vol\% $\mathrm{CO}_{2}$ injection for $5 \mathrm{~min}$. The total flow rate was always kept at $100 \mathrm{ml} \mathrm{min}{ }^{-1}$. (b and c) TEM images of exRuCeO after the 20 chemical loops of methane reforming coupled with $\mathrm{CO}_{2}$ splitting, illustrating the stability of the exsolved Ru nanoparticles. In (c) the interplanar distance of the exsolved particle after 20 cycles is illustrated.

exRuCeO ${ }_{2}$ material is preserved, although some differences with respect to the chemical looping test in Fig. 6d are visible. First, regarding the $\mathrm{CO}$ production during the $\mathrm{CO}_{2}$ splitting step; with the increase in the vol\% of $\mathrm{CO}_{2}$, the peak production rate is greatly enhanced. That is to say, in Fig. $6 \mathrm{~d}$ we observe a peak production rate of $24.9 \mathrm{~mL} \mathrm{~min}^{-1} \mathrm{~g}^{-1}$ when using $5 \mathrm{vol} \%$ of $\mathrm{CO}_{2}$, whereas when increasing the concentration up to $50 \mathrm{vol} \%$, the rate increases up to $189.9 \mathrm{~mL} \mathrm{~min}^{-1} \mathrm{~g}^{-1}$, which is about a 7 -fold increase. However, this high value was not maintained during the whole cycling test, and after a small decrease in the second

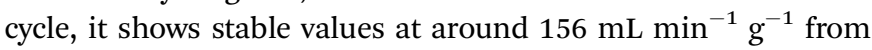
the 6 th to the 20th cycle. To put these results into perspective, Ruan et al. reported $168.8 \mathrm{~mL} \mathrm{~min}^{-1} \mathrm{~g}^{-1}$ using $100 \mathrm{vol} \% \mathrm{CO}_{2}$ and Ti-doped $\mathrm{CeO}_{2}$ impregnated with metallic Ni. ${ }^{20}$ In addition, on increasing the vol\% of $\mathrm{CO}_{2}$ the reaction reached equilibrium in ca. $1 \mathrm{~min}$ (see Fig. S5 in the ESI $\dagger$ ). This fact indicates that complete equilibration in $\mathrm{CO}_{2}$ via re-oxidation is achieved, and, thus, in the subsequent MPO step, the effect of additional oxygen vacancies - generated upon exsolution - as active sites for the activation of methane could be ruled out. Indeed, when comparing the syngas production curves between the first methane injection and the second, this effect becomes evident. That is to say, during the first MPO reaction, the $\mathrm{H}_{2}$ production is $34.4 \mathrm{~mL} \mathrm{~min}{ }^{-1} \mathrm{~g}^{-1}$, which is very close to the reported value in Fig. 6 a wherein the same conditions of $5 \mathrm{vol} \%$ of $^{\mathrm{CH}_{4}}$ and $900{ }^{\circ} \mathrm{C}$ were employed. However, in the second cycle the peak $\mathrm{H}_{2}$ production rate lowers down to $23.4 \mathrm{~mL} \mathrm{~min}{ }^{-1} \mathrm{~g}^{-1}$, which is ascribed to the initial lack of surface oxygen vacancies that help in activating MPO. Thus, after the first cycle, since high $\mathrm{CO}_{2}$ concentrations are used and, hence, full oxidation achieved, the catalytic improvement for the MPO could be solely ascribed to the exsolved Ru nanoparticles. Importantly, from the 2nd to the 20th cycle the MPO performance was stable (Fig. 8a) with a $\mathrm{H}_{2}$ production rate around $23.4 \mathrm{~mL} \mathrm{~min}^{-1} \mathrm{~g}^{-1}$.

Next, we assessed the microstructural stability of the exsolved $\mathrm{Ru}$ nanoparticles after the 20-cycle longevity test depicted in Fig. 8a. For that purpose, we analyzed with TEM the materials after reaction (Fig. 8b and c). In Fig. 8b, we provide evidence for the existence of Ru nanoparticles that remained well dispersed over the oxide surface after the multi-cycle treatment at high temperatures. Since the images were taken after the last $\mathrm{CO}_{2}$ splitting step, this also proves that the exsolved Ru nanoparticles are not dissolved back into the lattice under these experimental conditions used in the oxidation step. This is probably due to the short exposure $(5 \mathrm{~min})$ to a less oxidative atmosphere $\left(\mathrm{CO}_{2}\right)$ when compared to air, which is the gas used in re-dissolution treatments. Thus, under these oxidative conditions there is not enough driving force to produce the dissolution of the exsolved

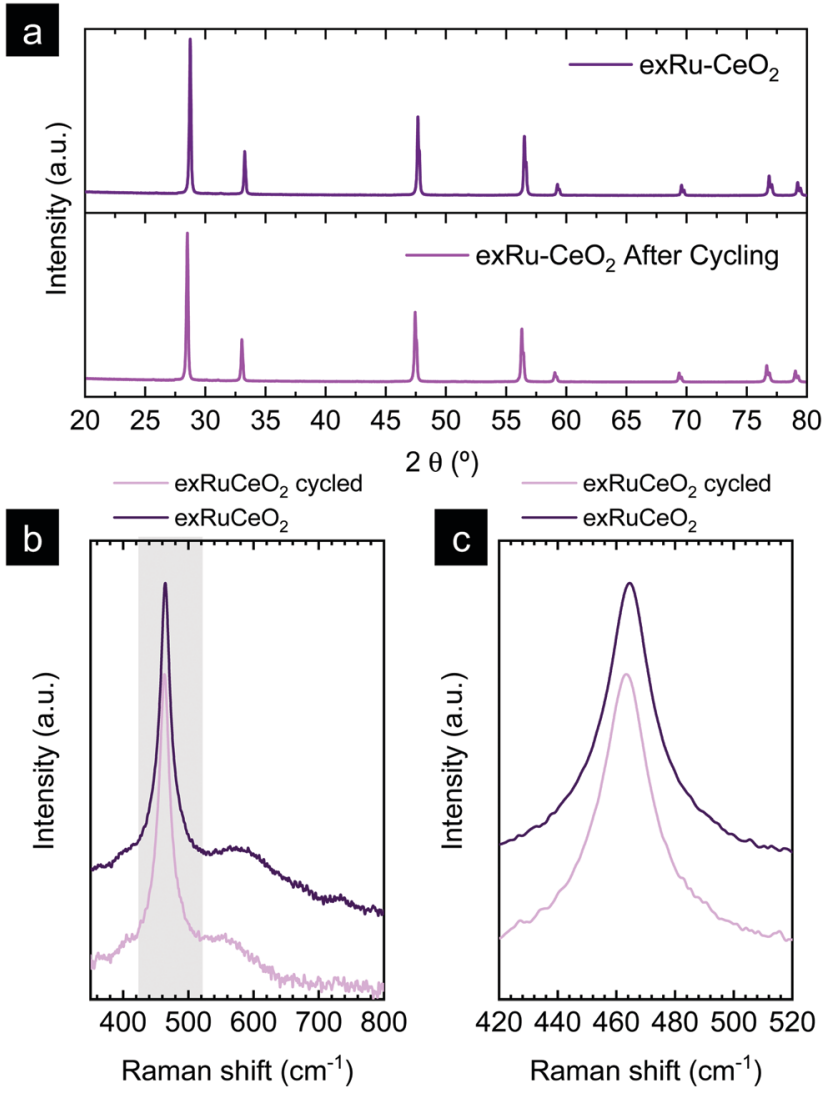

Fig. 9 (a) XRD diffractograms comparing exRuCeO 2 before and after the 20-cycle chemical looping reforming test. (b) Raman spectra comparison of exRuCeO $\mathrm{C}_{2}$ before and after 20 cycles. They grey-shaded region is zoomed out in (c) to show the shift of the $F_{2 \mathrm{~g}}$ peak towards lower Raman shift values. The Raman spectra were collected with a $785 \mathrm{~cm}^{-1}$ laser. 
$\mathrm{Ru}$ nanoparticles back to the ceria backbone. This fact was previously reported with Co exsolution in $\mathrm{La}_{0.6} \mathrm{Sr}_{0.4} \mathrm{Cr}_{0.8} \mathrm{Co}_{0.2} \mathrm{O}_{3}$ perovskites. $^{32}$ The nanoparticles of 4-5 nm remained welldispersed and anchored to the oxide backbone, which prevented nanoparticle agglomeration. Fig. 8c provides further evidence of the level of anchoring. The interplanar distance of the exsolved nanoparticle was determined to be equal to $0.205 \mathrm{~nm}$, which corresponds to the (101) orientation in metallic $\mathrm{Ru}$, which further corroborates the nature of the exsolved nanoparticles.

The X-ray diffractogram of exRuCeO $\mathrm{O}_{2}$ before and after the 20 chemical looping reforming cycles is depicted in Fig. 9a. After cycling, the material presented the peaks associated with the fluorite crystal structure. However, the calculated cubic lattice parameter was $5.422 \AA$, whereas before reaction it was $5.413 \AA$, indicating lattice expansion upon cycling, returning to lattice volume values similar to the material before exsolution $\left(a=5.421 \AA\right.$ for $\left.\mathrm{Ru}-\mathrm{CeO}_{2}\right)$. Raman spectroscopy was employed to further analyze the structural changes after multiple cycling (Fig. 9b and c). Fig. 9b reveals that after cycling the $F_{2 \mathrm{~g}}$ vibration is still the main component. However, as observed in the zoom-out area depicted in Fig. 9c, the $F_{2 \mathrm{~g}}$ shifted towards lower wavenumbers, with respect to the freshly exsolved material. That is to say, after 20 cycles the $F_{2 \mathrm{~g}}$ peak value moved to $463.1 \mathrm{~cm}^{-1}$, whereas before reaction it was $464.5 \mathrm{~cm}^{-1}$, displacement that confirms the lattice expansion observed by XRD analysis.

In summary, in this section we proved both the microstructural and chemical stability of the $\mathrm{Ru}$ nanoparticles over prolonged cycling at high temperatures, which remarks the key benefits of applying exsolution in high temperature thermocatalytic processes.

\section{Conclusions}

In this work, we have synthesized $\mathrm{CeO}_{2}$ decorated with $\mathrm{Ru}$ nanoparticles of $c a .5 \mathrm{~nm}$ via the exsolution method and tested its activity for chemical looping reforming of methane coupled with $\mathrm{CO}_{2}$ splitting, to address the main limitations that bare $\mathrm{CeO}_{2}$ presents in this process. With TEM, EDX and XPS we provide proof of $\mathrm{Ru}$ nanoparticle exsolution and anchorage on $\mathrm{CeO}_{2}$ for the first time, which were well dispersed all over the oxide surface. The chemical-looping reforming activity was tested and compared against reference - undoped - $\mathrm{CeO}_{2}$, observing a remarkable increase in the syngas yield and production rate as well as carbon monoxide selectivity of $99 \%$ at $700{ }^{\circ} \mathrm{C}$. Particularly remarkable is the syngas production result at such temperature, which matches perfectly operation utilizing industrial waste heat. That is to say, at $700{ }^{\circ} \mathrm{C}$, a peak $\mathrm{H}_{2}$

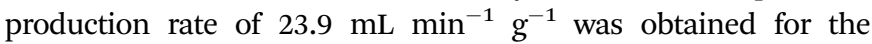
material decorated with exsolved $\mathrm{Ru}$ nanoparticles, whereas for bare $\mathrm{CeO}_{2}$ it was just $0.18 \mathrm{~mL} \mathrm{~min} \mathrm{~m}^{-1} \mathrm{~g}^{-1}$, which is two orders of magnitude less. Finally, the durability of the process was tested for 20 consecutive chemical loops denoting the remarkable stability of the morphology of exsolved nanoparticles after prolonged cycling. In summary, the findings presented here confirm the robustness of $\mathrm{CeO}_{2}$-surface-anchored exsolved $\mathrm{Ru}$ nanoparticles as catalysts in high temperature thermochemical processes.

\section{Experimental methods}

\subsection{Material synthesis}

$\mathrm{CeO}_{2}$ and $\mathrm{Ru}_{0.01} \mathrm{Ce}_{0.99} \mathrm{O}_{2}\left(\mathrm{Ru}-\mathrm{CeO}_{2}\right)$ were synthesized by a modified version of the Pechini method. Cerium(III)nitrate $\left(\mathrm{Ce}\left(\mathrm{NO}_{3}\right)_{3} \cdot 6 \mathrm{H}_{2} \mathrm{O}\right.$, 99\%; Sigma Aldrich-Merck) and ruthenium(III)nitrosyl nitrate solution $\left(\mathrm{Ru}(\mathrm{NO})\left(\mathrm{NO}_{3}\right)_{x}(\mathrm{OH})_{y}, x+y=3,1.5 \% \mathrm{Ru}\right.$; Sigma AldrichMerck) were dissolved in an aqueous solution of citric acid (CA, 99\%; Sigma Aldrich-Merck) at $60{ }^{\circ} \mathrm{C}$ under constant stirring for $3 \mathrm{~h}$, using a metal precursor: CA molar ratio of $1: 1.5$. Afterward, ethylene glycol (EG, 99\%; Sigma Aldrich-Merck) was added to the mixture to a CA:EG ratio of $2 / 3 \mathrm{wt} \%$ and the temperature was increased to $80{ }^{\circ} \mathrm{C}$ for $2 \mathrm{~h}$. After most of the solution was evaporated, it was transferred to a drying oven and heated at $220{ }^{\circ} \mathrm{C}$ overnight, during which gelification and calcination of the gel took place. Then, the dry powder was ground into a fine powder using an agate mortar and calcined at $1000{ }^{\circ} \mathrm{C}$ for $10 \mathrm{~h}$ to obtain the fluorite phase. Nanoparticle exsolution on $\mathrm{Ru}-\mathrm{CeO}_{2}$ was performed in a horizontal tubular furnace at $900{ }^{\circ} \mathrm{C}$, during $2 \mathrm{~h}$ under $5 \% \mathrm{H}_{2} / \mathrm{Ar}$ flow, unless otherwise specified in the text.

\subsection{Physicochemical characterization}

X-ray diffractometry (XRD) was performed utilizing a PANalytical CubiX fast diffractometer using $\mathrm{CuK} \alpha 1,2$ radiation and a $\mathrm{X}$ 'Celerator detector in Bragg-Brentano geometry. XRD patterns were recorded in the $2 \theta$ range $20^{\circ}$ to $90^{\circ}$ and analyzed using the software X'Pert Highscore Plus.

X-ray photoelectron spectra were collected by using a SPECS spectrometer equipped with a Phibos 150 MCD-9 detector and by using a non-monochromatic AlKa (1486.6 eV) X-ray source and charge compensation by means of additional electron flow. Spectra were recorded by using an analyzer pass energy of $50 \mathrm{eV}$ and an $\mathrm{X}$-ray power of $100 \mathrm{~W}$ under an operating pressure of $10^{-9} \mathrm{mbar}$. During data processing of the XPS spectra, the binding energy (BE) values were referenced to $\mathrm{C} 1 \mathrm{~s}$ (peak at $\mathrm{BE}=248.8 \mathrm{eV}$ ). Spectra treatment was performed using CasaXPS processing software.

Raman spectroscopy was performed using a Renishaw Raman spectrometer. Analyses were conducted at room temperature with a $785 \mathrm{~nm}$ laser equipped with an Olympus microscope and a CCD detector.

The morphology of the synthesized oxides was analyzed via scanning electron microscopy (SEM) using a GeminiSEM 500 from Zeiss and transmission electron microscopy (TEM) using a JEM 2100F $200 \mathrm{kV}$ field emission microscope equipped with a Gatan OneView camera. Energy dispersive X-ray spectroscopy elemental point scan analyses were conducted using EDS X-Max 80 de Oxford Instruments, with a $127 \mathrm{eV}$ resolution.

The Micromeritics system was used to carry out temperatureprogrammed reduction (TPR). $100 \mathrm{mg}$ of sample was pelletized and degassed under Ar flow for $1 \mathrm{~h}$ and then was subjected to reduction under $\mathrm{H}_{2} / \mathrm{Ar}$ (1/9) flow, with a heating rate of $10{ }^{\circ} \mathrm{C} \min ^{-1}$ until $950{ }^{\circ} \mathrm{C} . \mathrm{H}_{2}$ consumption was measured by using a TCD.

\subsection{Chemical looping reforming test}

Chemical looping reforming of methane coupled with $\mathrm{CO}_{2}$ splitting was carried out in a fixed-bed reactor setup. The 
reactor consisted of a quartz tube of $\frac{1}{2}$ inch inner diameter placed inside a tubular vertical electrical furnace. The oxide samples $(0.265 \mathrm{~g})$ were placed over a quartz frit located at half of the quartz tube (total length $41 \mathrm{~cm}$ ). The temperature was controlled with a K-type thermocouple in contact with the oxide bed and covered by a quartz shield. For the reaction tests, the materials were pressed into pellets, crushed and sieved for the size between 200 and $400 \mu \mathrm{m}$. The gas production was monitored using a Thermostar mass spectrometer from Pfeiffer, which was calibrated by flowing known gas concentrations before each reaction. In a typical experiment, the temperature was raised to $900{ }^{\circ} \mathrm{C}$ under an $\mathrm{Ar}$ (Praxair) atmosphere $\left(100 \mathrm{~mL} \mathrm{~min}^{-1}\right)$. Then, the materials were pretreated under $5 \%$ $\mathrm{H}_{2}$ balanced with Ar atmosphere for $2 \mathrm{~h}$ to drive the nanoparticle exsolution, unless otherwise specified. Afterward, each chemical loop consisted of $5 \mathrm{~min}$ injections of first, $5 \% \mathrm{CH}_{4}$, and second, $5 \% \mathrm{CO}_{2}$, both balanced in Ar. Between both injections, Ar was flowed to purge the reactor of reactive gases for $2 \mathrm{~min}$. The gas bottles were of $10 \% \mathrm{CH}_{4}$ balanced in $\mathrm{Ar}$ and $15 \% \mathrm{CO}_{2}$ balanced in Ar.

For the longevity test consisting of 20 chemical loops, a thinner quartz tube was used with an internal diameter of $0.7 \mathrm{~cm}$. In addition, for the oxidation step a stream of $50 \mathrm{vol} \%$ of $\mathrm{CO}_{2}$ was used utilizing a $100 \% \mathrm{CO}_{2}$ gas bottle and a total gas flow of $100 \mathrm{~mL} \mathrm{~min}^{-1}$.

$\mathrm{CO}_{2}$ and $\mathrm{CO} \mathrm{m} / \mathrm{z}$ signal overlapping was corrected through the following equation according to Sastre et al. ${ }^{57}$

$$
[\mathrm{CO}]=S(m / z=28)-f \cdot(m / z=44)
$$

where $f$ is the ratio between $\mathrm{m} / z=28$ and $\mathrm{m} / z=44$ mass spectrometry signals, which is calculated by flowing $\mathrm{CO}_{2}$ at concentrations of $15,7.5$ and 5 vol\%, balanced with $\mathrm{Ar}$ in an empty reactor at room temperature.

The carbon monoxide selectivity $\left(S_{\mathrm{CO}}\right)$ and $\mathrm{CH}_{4}$ and $\mathrm{CO}_{2}$ conversion $\left(X_{\mathrm{CH}_{4}}\right.$ and $X_{\mathrm{CO}_{2}}$ respectively) were calculated as follows, where $n_{\mathrm{CO}}, n_{\mathrm{CH}_{4}}$ and $n_{\mathrm{CO}_{2}}$ are the moles of $\mathrm{CO}, \mathrm{CH}_{4}$ and $\mathrm{CO}_{2}$ as integrated with time for the $\mathrm{CO}, \mathrm{CH}_{4}$ and $\mathrm{CO}_{2}$ profiles respectively:

$$
\begin{gathered}
S_{\mathrm{CO}}=\frac{n_{\mathrm{CO}}}{n_{\mathrm{CO}}+n_{\mathrm{CO}_{2}}} \\
X_{\mathrm{CH}_{4}}=\frac{n_{\mathrm{CH}_{4, \text { in }}}-n_{\mathrm{CH}_{4, \text { out }}}}{n_{\mathrm{CH}_{4, \text { in }}}} \\
X_{\mathrm{CO}_{2}}=\frac{n_{\mathrm{CO}_{2, \text { in }}}-n_{\mathrm{CO}_{2, \text { out }}}}{n_{\mathrm{CO}_{2, \text { in }}}}
\end{gathered}
$$

The oxygen supply capacity was calculated using the following equation, adapted from ref. 30 :

$$
\zeta=\frac{n_{\mathrm{H}_{2}}}{m} \times M_{\text {ceria }}
$$

where $\zeta$ is the oxygen supply capacity of the oxide in mol $\mathrm{O}$ mol $_{\text {oxide }}{ }^{-1}, n_{\mathrm{H}_{2}}$ is the $\mathrm{H}_{2}$ moles consumed by the oxide determined by TPR analyses, $m$ is the mass of the sample measured by TPR, and $M_{\text {ceria }}$ is the molecular mass of the cerium oxides tested.

\section{Conflicts of interest}

The authors declare no conflict of interest.

\section{Acknowledgements}

AJC and MB would like to acknowledge the support of Juan de la Cierva fellowships by the Spanish Ministry of Science (grant numbers FJCI-2017-33967 and IJCI-2017-34110). We acknowledge the support of the Electronic Microscopy Service of the Universitat Politècnica de València.

\section{References}

1 A. Thursfield, A. Murugan, R. Franca and I. S. Metcalfe, Energy Environ. Sci., 2012, 5, 7421-7459.

2 X. Zhu, F. Donat, Q. Imtiaz, C. R. Müller and F. Li, Energy Environ. Sci., 2020, 14, 112.

3 J. Garcia-Fayos, J. M. Serra, M. W. J. Luiten-Olieman and W. A. Meulenberg, Gas separation ceramic membranes, 2020.

4 A. J. Carrillo, J. L. M. Rupp and J. M. Coronado, in Energy Storage and Conversion Materials, ed. S. J. Skinner, The Royal Society of Chemistry, Inorganic, 2020, pp. 136-187.

5 V. P. Haribal, X. Wang, R. Dudek, C. Paulus, B. Turk, R. Gupta and F. Li, Adv. Energy Mater., 2019, 9, 1901963.

6 P. T. Krenzke, J. R. Fosheim and J. H. Davidson, Sol. Energy, 2017, 156, 48-72.

7 C. Agrafiotis, H. Von Storch, M. Roeb and C. Sattler, Renewable Sustainable Energy Rev., 2014, 29, 656-682.

8 J. Zhang, V. Haribal and F. Li, Sci. Adv., 2017, 3, e1701184.

9 K. J. Warren, R. J. Carrillo, B. Greek, C. M. Hill and J. R. Scheffe, Energy Technol., 2020, 8, 2000053.

10 R. J. Carrillo and J. R. Scheffe, Sol. Energy, 2017, 156, 3-20.

11 K. J. Warren, J. Reim, K. Randhir, B. Greek, R. Carrillo, D. W. Hahn and J. R. Scheffe, Energy Technol., 2017, 5, 2138-2149.

12 M. Welte, K. Warren, J. R. Scheffe and A. Steinfeld, Ind. Eng. Chem. Res., 2017, 56, 10300-10308.

13 S. Chuayboon, S. Abanades and S. Rodat, Chem. Eng. J., 2019, 356, 756-770.

14 Y. Zheng, X. Zhu, H. Wang, K. Li, Y. Wang and Y. Wei, J. Rare Earths, 2014, 32, 842-848.

15 X. Gao, A. Vidal, A. Bayon, R. Bader, J. Hinkley, W. Lipiński and A. Tricoli, J. Mater. Chem. A, 2016, 4, 9614-9624.

16 Y. Chen, X. Zhu, K. Li, Y. Wei, Y. Zheng and H. Wang, ACS Sustainable Chem. Eng., 2019, 7, 15452-15462.

17 X. Gao, G. Liu, Y. Zhu, P. Kreider, A. Bayon, T. Gengenbach, T. Lu, Y. Liu, J. Hinkley, W. Lipiński and A. Tricoli, Nano Energy, 2018, 50, 347-358.

18 X. Gao, I. Di Bernardo, P. Kreider, T. Tran-Phu, X. Cai, N. Wang, Y. Zhu, M. B. Venkataraman, J. Lipton-Duffin, A. Bayon, W. Lipiński and A. Tricoli, ACS Catal., 2019, 9880-9890.

19 M. Fathi, E. Bjorgum, T. Viig and O. Rokstad, Catal. Today, 2000, 63, 489-497. 
20 C. Ruan, Z.-Q. Huang, J. Lin, L. Li, X. Liu, M. Tian, C. Huang, C.-R. Chang, J. Li and X. Wang, Energy Environ. Sci., 2019, 12, 767-779.

21 T. W. Hansen, A. T. DeLaRiva, S. R. Challa and A. K. Datye, Acc. Chem. Res., 2013, 46, 1720-1730.

22 D. Neagu, G. Tsekouras, D. N. Miller, H. Menard and J. T. Irvine, Nat. Chem., 2013, 5, 916-923.

23 D. Neagu, T. S. Oh, D. N. Miller, H. Menard, S. M. Bukhari, S. R. Gamble, R. J. Gorte, J. M. Vohs and J. T. Irvine, Nat. Commun., 2015, 6, 8120.

24 J. T. S. Irvine, D. Neagu, M. C. Verbraeken, C. Chatzichristodoulou, C. Graves and M. B. Mogensen, Nat. Energy, 2016, 1, 15014.

25 B. Hua, M. Li, Y. F. Sun, J. H. Li and J. L. Luo, ChemSusChem, 2017, 10, 3333-3341.

26 K. Kousi, D. Neagu, L. Bekris, E. I. Papaioannou and I. S. Metcalfe, Angew. Chem., Int. Ed., 2020, 59, 2510-2519.

27 M. A. Naeem, P. M. Abdala, A. Armutlulu, S. M. Kim, A. Fedorov and C. R. Müller, ACS Catal., 2020, 10, 1923-1937.

28 Y. J. Wong, M. K. Koh, N. F. Khairudin, S. Ichikawa, Y. Morikawa and A. R. Mohamed, ChemCatChem, 2019, 11, 5593-5605.

29 S. Vecino-Mantilla, P. Gauthier-Maradei, M. Huvé, J. M. Serra, P. Roussel and G. H. Gauthier, ChemCatChem, 2019, 11, 4631-4641.

30 K. Kousi, D. Neagu, L. Bekris, E. Calì, G. Kerherve, E. I. Papaioannou, D. J. Payne and I. S. Metcalfe, J. Mater. Chem. A, 2020, 8, 12406-12417.

31 G. Dimitrakopoulos, A. F. Ghoniem and B. Yildiz, Sustainable Energy Fuels, 2019, 3, 2347-2355.

32 A. J. Carrillo, K. J. Kim, Z. D. Hood, A. H. Bork and J. L. M. Rupp, ACS Appl. Energy Mater., 2020, 1-34.

33 T. Montini, M. Melchionna, M. Monai and P. Fornasiero, Chem. Rev., 2016, 116, 5987-6041.

34 Y. Chen, B. DeGlee, Y. Tang, Z. Wang, B. Zhao, Y. Wei, L. Zhang, S. Yoo, K. Pei, J. H. Kim, Y. Ding, P. Hu, F. F. Tao and M. Liu, Nat. Energy, 2018, 3, 1042-1050.

35 X. Shen, T. Chen, S. R. Bishop, N. H. Perry, H. L. Tuller and K. Sasaki, J. Power Sources, 2017, 370, 122-130.

36 J. M. Serra, J. F. Borrás-Morell, B. García-Baños, M. Balaguer, P. Plaza-González, J. Santos-Blasco, D. Catalán-Martínez, L. Navarrete and J. M. Catalá-Civera, Nat. Energy, 2020, 5, 910-919.

37 R. D. Shannon, Acta Crystallogr., Sect. A: Cryst. Phys., Diffr., Theor. Gen. Crystallogr., 1976, 32, 751-767.
38 P. Singh and M. S. Hegde, Chem. Mater., 2009, 21, 3337-3345.

39 S. Sharma, Z. Hu, P. Zhang, E. W. McFarland and H. Metiu, J. Catal., 2011, 278, 297-309.

40 R. Schmitt, A. Nenning, O. Kraynis, R. Korobko, A. I. Frenkel, I. Lubomirsky, S. M. Haile and J. L. M. Rupp, Chem. Soc. Rev., 2020, 49, 554-592.

41 E. Sediva, A. J. Carrillo, C. E. Halloran and J. L. M. Rupp, ACS Appl. Energy Mater., 2021, 4, 1474-1483.

42 H. Han, J. Park, S. Y. Nam, K. J. Kim, G. M. Choi, S. S. P. Parkin, H. M. Jang and J. T. S. Irvine, Nat. Commun., 2019, 10, 1471.

43 C. L. Muhich, J. Phys. Chem. C, 2017, 121, 8052-8059.

44 C. Solís, M. Balaguer and J. M. Serra, Membranes, 2020, 10, 1-16.

45 M. Balaguer, C. Solís and J. M. Serra, Chem. Mater., 2011, 23, 2333-2343.

46 M. Balaguer, C. Solís, S. Roitsch and J. M. Serra, Dalton Trans., 2014, 43, 4305-4312.

47 Y. Gao, D. Chen, M. Saccoccio, Z. Lu and F. Ciucci, Nano Energy, 2016, 27, 499-508.

48 J. Spring, E. Sediva, Z. D. Hood, J. C. Gonzalez-Rosillo, W. O'Leary, K. J. Kim, A. J. Carrillo and J. L. M. Rupp, Small, 2020, 16, 2003224.

49 D. Neagu, V. Kyriakou, I. Roiban, M. Aouine, C. Tang, A. Caravaca, K. Kousi, I. Schreur-Piet, I. S. Metcalfe, P. Vernoux, M. C. M. van de Sanden and M. N. Tsampas, ACS Nano, 2019, 13, 12996-13005.

50 J. Moulder, W. Stickle, P. Sobol and K. Bomben, Handbook of $X$-ray photoelectron spectroscopy, 1992.

51 C. Yang, X. Yu, S. Heißler, A. Nefedov, S. Colussi, J. Llorca, A. Trovarelli, Y. Wang and C. Wöll, Angew. Chem., Int. Ed., 2017, 56, 375-379.

52 E. Bêche, P. Charvin, D. Perarnau, S. Abanades and G. Flamant, Surf. Interface Anal., 2008, 40, 264-267.

53 J. F. Moulder, Handbook of X-ray photoelectron spectroscopy, physical electronics, 1995.

54 P. T. Krenzke, J. R. Fosheim, J. Zheng and J. H. Davidson, Int. J. Hydrogen Energy, 2015, 41, 12799-12811.

55 K. J. Warren and J. R. Scheffe, J. Phys. Chem. C, 2019, 123, 13208-13218.

56 S. Ackermann, L. Sauvin, R. Castiglioni, J. L. M. Rupp, J. R. Scheffe and A. Steinfeld, J. Phys. Chem. C, 2015, 119, 16452-16461.

57 D. Sastre, D. P. Serrano, P. Pizarro and J. M. Coronado, J. $\mathrm{CO}_{2}$ Util., 2019, 31, 16-26. 